\title{
Retraction Note to: Determination of dopant of ceria system by density functional theory
}

\author{
K. Muthukkumaran ${ }^{1} \cdot \operatorname{Roshan}_{\text {Bokalawela }}{ }^{1} \cdot$ Tom Mathews $^{3} \cdot$ S. Selladurai $^{1}$
}

Received: 1 February 2016/ Accepted: 1 February 2016/Published online: 12 February 2016

(C) Springer Science+Business Media New York 2016

\section{Retraction Note to: J Mater Sci (2007) 42:7461-7466 DOI 10.1007/s10853-006-1486-5}

Following detailed consultation with the Editor-in-Chief, the publisher has retracted this article, since it plagiarizes a paper entitled "Optimization of ionic conductivity in doped ceria" which was authored by D. A. Andersson, S.I. Simak, N.V. Skorodumova, I.A. Abrikosov, and B. Johansson, published in Proceedings of the National Academy of Science in 2006 103:3518-3521.

The online version of the original article can be found under doi:10.1007/s10853-006-1486-5.

\section{S. Selladurai}

ssdurai@yahoo.com

1 Department of Physics, Anna University, Chennai, Tamil Nadu 600025, India

2 Homer L. Dodge Department of Physics and Astronomy, The University of Oklahoma, Norman, USA

3 Surface science Section, Materials Science Division, IGCAR, Kalpakkam 603102, India 